\title{
Carotenoid intake and head and neck cancer: a pooled analysis in the International Head and Neck Cancer Epidemiology Consortium
}

\author{
Emanuele Leoncini ${ }^{1}$, Valeria Edefonti ${ }^{2}$, Mia Hashibe ${ }^{3}$, Maria Parpinel ${ }^{4}$, Gabriella Cadoni ${ }^{5}$, \\ Monica Ferraroni ${ }^{2}$, Diego Serraino ${ }^{6}$, Keitaro Matsuo 7 , Andrew F. Olshan ${ }^{8}$, Jose P. Zevallos ${ }^{8}$, \\ Deborah M. Winn ${ }^{9}$, Kirsten Moysich ${ }^{10}$, Zuo-Feng Zhang ${ }^{11}$, Hal Morgenstern ${ }^{12}$, Fabio Levi ${ }^{13}$, \\ Karl Kelsey ${ }^{14}$, Michael McClean ${ }^{15}$, Cristina Bosetti ${ }^{16}$, Stimson Schantz ${ }^{17}$, Guo-Pei Yu ${ }^{18}$, \\ Paolo Boffetta ${ }^{19}$, Yuan-Chin Amy Lee ${ }^{3}$, Shu-Chun Chuang ${ }^{20}$, Adriano Decarli' ${ }^{2}$, Carlo La \\ Vecchia $^{2}$, and Stefania Boccia ${ }^{1}$
}

${ }^{1}$ Section of Hygiene, Institute of Public Health, Università Cattolica del Sacro Cuore, Largo F. Vito, 1, 00168 Rome, Italy ${ }^{2}$ Department of Clinical Sciences and Community Health, University of Milan, Milan, Italy ${ }^{3}$ Division of Public Health, Department of Family and Preventive Medicine, Huntsman Cancer Institute, University of Utah School of Medicine, Salt Lake City, UT, USA ${ }^{4}$ Department of Medical and Biological Sciences, Institute of Hygiene and Epidemiology, University of Udine, Udine, Italy ${ }^{5}$ Institute of Otorhinolaryngology, Università Cattolica del Sacro Cuore, Rome, Italy ${ }^{6}$ Aviano Cancer Centre, Aviano, Italy ${ }^{7}$ Faculty of Medical Sciences, Kyushu University, Kyushu, Japan ${ }^{8}$ School of Public Health, University of North Carolina, Chapel Hill, NC, USA ${ }^{9}$ National Cancer Institute, Bethesda, MD, USA ${ }^{10}$ Roswell Park Cancer Institute, Buffalo, NY, USA ${ }^{11}$ UCLA School of Public Health, Los Angeles, CA, USA ${ }^{12}$ Departments of Epidemiology and Environmental Health Sciences, School of Public Health and Comprehensive Cancer Center, University of Michigan, Ann Arbor, MI, USA ${ }^{13}$ Institut Universitaire de Medecine Sociale et Preventive (IUMSP), Centre Hospitalier Universitaire Vaudois, University of Lausanne, Lausanne, Switzerland ${ }^{14}$ Brown University, Providence, RI, USA ${ }^{15}$ Boston University School of Public Health, Boston, MA, USA ${ }^{16}$ Department of Epidemiology, IRCCS-Istituto di Ricerche Farmacologiche Mario Negri, Milan, Itlay ${ }^{17} \mathrm{New}$ York Eye and Ear Infirmary, New York, NY, USA ${ }^{18}$ Medical Informatics Center, Peking University, Beijing, China ${ }^{19}$ The Tisch Cancer Institute and Institute of Translational Epidemiology, Icahn School of Medicine at Mount Sinai, New York, NY, USA

${ }^{20}$ Institute of Population Health Sciences, National Health Research Institutes, Zhunan, Taiwan

\begin{abstract}
Food and nutrition play an important role in head and neck cancer (HNC) etiology; however, the role of carotenoids remains largely undefined. We explored the relation of HNC risk with the intake of carotenoids within the International Head and Neck Cancer Epidemiology Consortium.
\end{abstract}

Correspondence to: Stefania Boccia.

Emanuele Leoncini, Valeria Edefonti, Carlo La Vecchia and Stefania Boccia have contributed equally to this work.

Electronic supplementary material: The online version of this article (doi:10.1007/s10654-015-0036-3) contains supplementary material, which is available to authorized users.

Conflict of interest: The authors declare no conflict of interest. 
We pooled individual-level data from 10 case-control studies conducted in Europe, North America, and Japan. The analysis included 18,207 subjects (4414 with oral and pharyngeal cancer, 1545 with laryngeal cancer, and 12,248 controls), categorized by quintiles of carotenoid intake from natural sources. Comparing the highest with the lowest quintile, the risk reduction associated with total carotenoid intake was $39 \%$ (95 \% CI 29-47 \%) for oral/pharyngeal cancer and $39 \%$ ( $95 \%$ CI $24-50 \%$ ) for laryngeal cancer. Intakes of $\beta$-carotene equivalents, $\beta$-cryptoxanthin, lycopene, and lutein plus zeaxanthin were associated with at least $18 \%$ reduction in the rate of oral and pharyngeal cancer (95\% CI 6-29\%) and $17 \%$ reduction in the rate of laryngeal cancer (95\% CI 0-32\%). The overall protective effect of carotenoids on HNC was stronger for subjects reporting greater alcohol consumption $(p<0.05)$. The odds ratio for the combined effect of low carotenoid intake and high alcohol or tobacco consumption versus high carotenoid intake and low alcohol or tobacco consumption ranged from 7 (95 \% CI 5-9) to 33 (95\% CI 23-49). A diet rich in carotenoids may protect against HNC. Persons with both low carotenoid intake and high tobacco or alcohol are at substantially higher risk of HNC.

\section{Keywords}

Carotenoids; Head and neck cancer; Nutrients; Diet

\section{Background}

Head and neck cancer (HNC) includes cancers of the oral cavity, pharynx and larynx, and it is one of the most common cancers worldwide [1]. Tobacco and alcohol are the main risk factors of HNCs, with human papillomavirus type 16 (HPV-16) being a well-established risk factor for oropharyngeal cancer [2].

Furthermore, food and nutrition play an important role in HNC etiology [3]. Several studies showed a favorable effect of fruit and vegetables in HNC risk [4-8]. In 2007, the World Cancer Research Fund and the American Institute for Cancer Research concluded that intakes of non-starchy vegetables and fruit probably protect against cancer of the mouth, pharynx, and larynx [3].

Carotenoids from fruit and vegetables may be responsible for some of these favorable effects, as they are well-known antioxidants with anti-mutagenic and immune-regulatory actions [9]. To date, more than 700 carotenoids have been identified [10]; of these, around 50 are present in a typical human diet [11]. According to their chemical composition, carotenoids can be classified into oxygenated carotenoids (e.g. $\beta$-cryptoxanthin, lutein, zeaxanthin), known as xanthophylls, and hydrocarbon carotenoids (e.g. alpha-carotene, $\beta$ carotene and lycopene), known as carotenes [12].

The role of carotenoids as important food components in the risk of cancers of the oral cavity, pharynx and larynx, however, remains largely undefined. Evidence from observational epidemiological studies tends to support an inverse association of $\mathrm{HNC}$ risk with carotenoid intake [13-22]. Furthermore, there is substantial interest in the potential role of specific carotenoids in HNC prevention. However, few case-control studies reported associations between the intake of specific carotenoids and $\mathrm{HNC}$ [18, 23-31]. 
In addition, little is known about the potential for an effect modification by smoking and drinking on the relation between carotenoids and HNC. Given the potential antioxidant effects of carotenoids, subjects who smoke or consume alcohol may gain more benefit from a higher carotenoid intake.

Within the International Head and Neck Cancer Epidemiology (INHANCE) Consortium [32], we aimed to explore the relationships between HNC risk and the intake of selected carotenoids ( $\beta$-cryptoxanthin, lycopene, and lutein plus zeaxanthin), as well as combined carotenoids ( $\beta$-carotene equivalents and total carotenoids). Given the large sample size, we planned a priori to stratify the results by cancer subtypes, and other covariates of interest, including smoking status and alcohol consumption.

\section{Materials and methods}

\section{Studies and selection of subjects}

This is a pooled analysis of case-control studies participating in the INHANCE Consortium [32] - an investigation established in 2004 based on the collaboration of research groups leading large, molecular epidemiology studies of $\mathrm{HNC}$ - which included populations from Europe, North America and Japan in which information on carotenoid intake was available from study-specific food frequency questionnaires (FFQs).

The present analysis included 10 case-control studies for which information about carotenoid intake and a number of potential confounding variables previously related to HNC risk [5, 33-35], was obtained. These studies were conducted in the United States [Boston, Buffalo, Los Angeles, Memorial Sloan Kettering Cancer Center (MSKCC) from New York City, North Carolina (2002-2006), US Multicenter], Europe [Italy Multicenter, Milan (2006-2009), and Switzerland], and Asia [Japan (2001-2005)].

Subjects were included if their tumor had been classified as an invasive cancer of oral cavity, oropharynx, hypopharynx, oral cavity or pharynx not otherwise specified, larynx, or HNC unspecified. Subjects with cancers of the salivary glands or of the nasal cavity/ear/paranasal sinuses were excluded. The International Classification of Diseases coding used for the classification into subsites was specified in detail previously [33].

Cases with missing information on the site of origin of their cancer were removed. Subjects with missing information on carotenoid intake were removed from the original data. Subjects with an implausible ( $<500$ or $>5500 \mathrm{kcal}$ ) non-alcohol energy intake or those having missing values on non-alcohol energy intake were excluded from the analysis.

The present dataset includes 18,207 subjects: 4414 with oral and pharyngeal cancer, 1545 with laryngeal cancer, and 12,248 controls. All data were cleaned and checked for internal consistency and clarifications were requested from the original investigators when needed. All studies included in this pooled analysis had approval from local ethics committees, and written informed consent was obtained from all study participants. Study characteristics of the 10 studies are reported in the appendix (Table 1). 


\section{Definition of the exposure}

For each subject, consumption of several food items in a reference period was assessed using study-specific FFQs. Study-specific food composition databases were then used to derive from the food items estimates of intakes of total energy and several macro- and micronutrients, including some carotenoids [36].

Information was available from the individual studies on the intakes of the following individual carotenoids: $\beta$-cryptoxanthin, lycopene, lutein plus zeaxanthin. Combined information on more than one carotenoid was provided in some original studies in the form of $\beta$-carotene equivalents, calculated as:

$$
\mu g \beta \text {-carotene equivalents }=\mu g \beta-\text { carotene }+1 / 2(\mu g \alpha-\text { carotene }+\mu g \beta-\text { cryptoxanthin }) \text {. }
$$

We also defined total carotenoid intake as the unweighted sum of $a$-carotene, $\beta$-carotene, $\beta$ cryptoxanthin, lycopene, and lutein plus zeaxanthin.

We carried out preliminary checks on carotenoid definitions, reference periods of intake and measurement units across studies. We extracted information on carotenoid intake from natural sources, and we consistently expressed these intakes on a daily base ( $\mu \mathrm{g} / \mathrm{day})$.

To assess the comparability of daily intakes across studies, we inspected the kernel density estimation plot representing the study-specific empirical distributions of carotenoid intake [37]. We also compared study-specific summary statistics across studies. As preliminary checks revealed appreciable differences in carotenoid intake across studies, we computed non-alcohol energy-adjusted carotenoid intake within each study [38].

\section{Statistical analysis}

Participants were grouped into five categories according to quintiles of "non-alcohol energyadjusted' intakes calculated on the overall sample of cases and controls. We estimated the odds ratios (OR) and the corresponding $95 \%$ confidence intervals (CI) of oral and pharyngeal cancer (including oral, oropharynx, hypopharynx, unspecified oral/pharynx cancer), and laryngeal cancer, separately, for each quintile category (compared with the lowest quintile, the reference group) using unconditional multiple logistic regression models [39].

The following variables were included in the regression equations: age (in 5 year categories), gender, education (junior high school or less, some high school, high school graduate, technical school/some college, college graduate), ethnicity (black, white/with hispanic, others), study center, cigarette smoking status (never, former, current), cigarette smoking intensity ( $\leq 0,11-20,>20$ cigarettes/day), cigarette smoking duration ( $\_0,>20$ years), cigar smoking status (never cigar user, ever smoked $\geq 100$ cigars in a lifetime), pipe smoking status (never pipe user, ever smoked $\geq 100$ pipes in a lifetime), alcohol drinking intensity $(<1$, $1-2,3-4, \geq 5$ drinks/day) and an interaction term between cigarette smoking intensity and alcohol drinking intensity. 
When the $p$ value for heterogeneity between studies was $<0.1$, we fitted the corresponding random intercept-random slope generalized linear mixed models. Separate analyses were carried out by anatomical subsite of oral and pharyngeal cancer. For both cancers, stratumspecific effect estimates were calculated by age, gender, education, geographic region, body mass index at time of interview, tobacco consumption, and alcohol consumption. The effect of the interaction between alcohol or tobacco consumption and total carotenoid intake was also assessed via likelihood ratio tests of significance comparing models including versus excluding a combined variable representing available combinations of alcohol (or tobacco) and intakes of total carotenoids below or above the median intake on the overall sample.

For total carotenoids, we carried out a sensitivity analysis to investigate the effect of the adjustment for four a priori selected nutrients, including vitamin $\mathrm{C}$, vitamin $\mathrm{E}$, monounsaturated fatty acids, and polyunsaturated fatty acids. In addition, we evaluated the potential interaction effect of those dietary factors with total carotenoids.

All $\mathrm{p}$ values were based on two-sided tests. Statistical analyses were performed separately for oral and pharyngeal cancer and laryngeal cancer and by anatomical subsite of oral and pharyngeal cancer and were done with Stata software (StataCorp. 2013. Stata Statistical Software: Release 13. College Station, TX: StataCorp LP) and the open-source statistical computing environment R [40].

\section{Results}

The study-specific median and inter-quintile range of unadjusted values of $\beta$-carotene equivalents, $\beta$-cryptoxanthin, lycopene, lutein plus zeaxanthin and total carotenoids, are presented in Table 1. The median values were higher in the Italian studies.

Table 2 shows the distribution of 5959 HNC cases and 12,248 controls according to age, gender and other selected characteristics, separately for oral and pharyngeal $(n=4414)$, and for laryngeal cancer cases $(n=1545)$. Overall, cases and controls had similar distributions by age and gender whereas controls had a higher education level than cases. Moreover, cases were more likely than controls to be cigarette smokers and alcohol drinkers.

Comparing the highest with the lowest quintile, the risk reduction associated with total carotenoid intake was $39 \%$ (95\% CI 29-47 \%) for oral/pharyngeal cancer and $39 \%$ (95\% CI $24-50 \%$ ) for laryngeal cancer. Intakes of $\beta$-carotene equivalents, $\beta$-cryptoxanthin, lycopene, and lutein plus zeaxanthin were associated with at least $18 \%$ reduction in the rate of oral/pharyngeal cancer (95\% CI 6-29\%) and $17 \%$ reduction in the rate of laryngeal cancer (95\% CI 0-32\%) (Table 3). When oral and pharyngeal cancers were evaluated separately, the inverse association of carotenoids persisted (data not shown).

Table 4 reports the ORs of oral and pharyngeal cancer for the highest versus the lowest quintile of carotenoid intake by category of selected covariates. There was no evidence of effect modification by age, gender, BMI and tobacco consumption, whereas appreciable heterogeneity of effect estimates was found across strata of education and geographic region for $\beta$-carotene equivalents and lutein plus zeaxanthin, as the observed protective effect was stronger in the European studies and among those with low educational level Appreciable 
heterogeneity was also detected across strata of alcohol consumption for total carotenoids ( $p$ $<0.01$ ), with a stronger inverse association for heavy drinkers. The ORs for the fifth quintile compared to the first one were 0.79 (95\% CI 0.64-0.97) for never or light drinkers, 0.54 (95\% CI 0.42-0.70) for moderate drinkers, and 0.40 (95\% CI 0.29-0.56) for heavy drinkers. Heterogeneity was also detected across combined strata of alcohol drinking and cigarette smoking for total carotenoids.

Table 5 shows the ORs of laryngeal cancer for carotenoid intake in strata of selected variables. Similarly to oral and pharyngeal cancer, appreciable heterogeneity was observed across strata of geographic region for every nutrient except lycopene, across strata of age for lutein plus zeaxanthin, across strata of education for $\beta$-carotene equivalents and across strata of alcohol consumption for total carotenoids. When the effect of the combined exposure to cigarette smoking and alcohol drinking was investigated, heterogeneity across different strata was found for $\beta$-cryptoxanthin.

Figure 1 shows the combined estimated effects of alcohol or tobacco consumption and total carotenoid intake on each type of cancer. For oral and pharyngeal cancer, compared to never and light drinkers ( $<1$ drink/day) in the high category of total carotenoid intake (above the median), moderate ( $\geq 1$ to $<5$ drinks/day) and heavy drinkers ( $\geq 5$ drinks/day) in either the low (equal to or below the median) or the high total carotenoid intake category had higher ORs, with values ranging approximately from 2.1 to 10.3 , for drinkers of 5 or more drinks per day in the low intake category ( $p$ for interaction $<0.01$ ). Compared to never smokers in the high total carotenoid intake category, former and current smokers in either the low or the high total carotenoid intake category had higher ORs, with values ranging approximately from 1.4 to 7.2, for current smokers of more than 20 cigarettes per day in the low intake category ( $p$ for interaction $<0.001$ ). Similarly, for laryngeal cancer, moderate and heavy drinkers or former and current smokers in either category of total carotenoid intake had a increased OR, with values of 6.7 and 33.5 in the category with the highest exposure to smoking or alcohol and the low exposure to total carotenoids (alcohol, $p$ for interaction $<0.001$; tobacco, $p$ for interaction $<0.001$ ).

The sensitivity analyses revealed no consistent interaction effect between the intake of each of the a priori selected putative confounding nutrients and total carotenoids, except for the case of monounsaturated fatty acids and oral and pharyngeal cancer ( $p$ for interaction 0.038 ). Even when the adjustment for the extra nutrient was significant, the point estimates of total carotenoid intake on oral and pharyngeal cancer and laryngeal cancer were not altered by the inclusion of the extra dietary adjustment variable (data not shown).

Supplementary Table 2 shows the Pearson correlation coefficients between the putative confounding nutrients and the individual and combined carotenoids. Correlation coefficients were modest, with most absolute values ranging between 0 and 0.40 .

\section{Discussion}

In this pooled analysis of 10 case-control studies within the INHANCE Consortium on 5959 cases and 12,248 controls, we found inverse associations between selected and total 
carotenoid intakes and oral/pharyngeal and laryngeal cancer. The risk reduction associated with total carotenoid intake was about $40 \%$ for both cancers sites, with $\beta$-carotene equivalents showing the strongest effect (around $45 \%$ of risk reduction) and lycopene the weakest (17\% of risk reduction).

To our knowledge, at least one cohort study [41] and 23 case-control studies [13-31, 42-45] investigated the association between the intake of carotenoids from dietary sources and HNC risk. A few papers based on case-control studies reported associations between the intake of specific carotenoids and HNC risk [18, 23-31]. In most [23-27, 29], but not all [18, 28, 30, $31]$, of these studies, inverse associations were reported for at least one carotenoid.

Specifically, an inverse association was reported for a-carotene [24, 26], $\beta$-carotene [24, 26, 29], $\beta$-cryptoxanthin [24-27], lycopene [23, 24, 26], and lutein plus zeaxanthin [24, 26].

Few of these studies assessed the associations among never-smokers, a group in which confounding by smoking, the predominant risk factor for HNC, is avoided [13, 26, 43, 44]. Several of these case-control studies were also included in the INHANCE Consortium [13, $18-21,24,26,27,30]$.

Only one cohort study of US postmenopausal women examined dietary intakes of carotene in relation to oral, pharyngeal and esophageal cancer [41]. That study found no consistent inverse associations for dietary intakes of carotene. However, interpretation of that study includes the possibility of a lack of statistical power to detect small but potentially important inverse associations because of the relatively small sample size.

Thus, the findings of these studies provide evidence for inverse associations between carotenoid intake and HNC risk. Several plausible mechanisms have been reported for such a favourable effect of carotenoids [46, 47]. Some of the carotenoids can function as a provitamin A, which would have an effect on cellular differentiation and proliferation [48, 49]. Moreover, carotenoids may act as antioxidants, quenching free radicals, reducing damage from reactive oxidant species, and inhibiting lipid peroxidation [46].

The average intake of individual carotenoids, in particular that of lycopene, differs substantially across studies. Given the different dietary traditions of the various populations, variation in the assessment of the exposure, and the capacity of FFQs in ranking subjects' intakes only, a degree of heterogeneity across studies was expected. However, when we restricted our analysis to studies that reported similar levels of intake of the individual carotenoids, the inverse association effect persisted.

In the present analysis, the association between intake of carotenoids and HNC risk differed by geographic region, with an apparently stronger inverse association in Europe. The reason for the heterogeneity between geographic regions is not clear; however, a similar pattern of risk was reported in a previous study on vitamin C within the INHANCE Consortium [50]. This can be partially explained by the structural differences of the individual questionnaires that may affect the calculation of carotenoid intake: number and adequacy of food items with respect to the nutrient of interest, frequency type and serving size [51].

Further, we assessed the association between carotenoid intake and HNC, specifically comparing results obtained in non-smokers and smokers, as well as in non-drinkers and 
drinkers [52]. The combination of low carotenoid intake and a high exposure to tobacco or alcohol led to 7- to over 30-fold excess risks of oral and pharyngeal, and laryngeal cancer. The substantially higher risks observed in this study in heavy alcohol and tobacco consumers reporting low carotenoid intake may be due, at least in part, to the role of carotenoids against oxidative stress [46]. Cigarette smoking and alcohol drinking, indeed cause oxidant stress, which increases DNA damage and, consequently, the malignant transformation of normal cells [13].

The inverse association between carotenoids from food sources and HNC risk may not be attributable to carotenoid intake per se, but rather may reflect other dietary patterns associated with better health or with other unmeasured confounders. For example, the consumption of a diet rich in carotenoids may simply reflect a diet characterized by a high consumption of fruit and vegetables, which are also abundant in other components, such as fibers and other antioxidants. Dietary carotenoids may be also acting as a marker for other correlated intakes that may, per se, be protective [53]. In the INHANCE dataset, we conducted separate studies on specific nutrients (e.g. vitamin $C$ and, folates) [36, 50], food groups and dietary behaviors $[35,54]$ as they relate to the risk of these malignancies. Findings from these studies suggest that higher intakes of folate and vitamin $\mathrm{C}$ from foods, may protect against cancers of the oral cavity and pharynx, and larynx, after controlling for potential confounding factors.

Several factors influence carotenoids bioavailability, absorption, breakdown, transport and storage $[47,55,56]$. Further, the interactions between different types of carotenoids and other food components may play a role [47]. For example, vitamins $\mathrm{C}$ and $\mathrm{E}$ and carotenoids can act synergistically on the risk of certain cancers [57].

However, the interactions between total carotenoids and the putatively related nutrients were not significant in general for either cancer site, with the exception of monounsaturated fatty acids and oral and pharyngeal cancer.

Our analysis had several strengths. The large sample size in our study allowed us to examine associations within subgroups of the study population with adequate statistical power. In most studies the response rate was high, for both cases and controls. We were able to adequately control for the potential confounding by tobacco smoking and alcohol drinking, having detailed information on smoking and alcohol duration and intensity [58]. We also applied uniform criteria to define our exposure of interest. Moreover, analyses by cancer site were consistent, which suggests that the action of carotenoids represents a general mechanism rather than a site-specific one.

In interpreting our results we acknowledge a few limitations. First, the results may be biased by a non differential misclassification of individual intakes of various nutrients due to measurement error, and differential misclassification due to recall bias [51]. Additionally, residual confounding by under adjustment for alcohol and tobacco intake might have caused a biased estimation of the effect of carotenoids of HNC [59, 60]. However, the inverse associations were consistent across strata of alcohol and tobacco and, if anything, stronger in 
heavy drinkers. Consequently, it is unlikely that residual confounding by tobacco and alcohol explain our findings.

Secondly, the absence of appreciable confounding by other putatively related nutrients is reflected in their generally moderate correlations with carotenoids. Thirdly, although we adjusted our estimates for major recognized risk factors for HNC, residual confounding from other dietary and non dietary factors (e.g. HPV, physical activity) cannot be excluded. Lastly, we did not consider the intakes from multivitamins and beta-carotene supplements; however, the bioavailability and absorption of synthetic form of carotenoids are different in comparison with to carotenoids from natural sources [61].

In summary, a diet rich in carotenoids may protect against HNC. This is also in line with information from a few large studies that analyzed the overall impact of carotenoids in relation to HNC. Subjects with both low carotenoid intake and high tobacco or alcohol use appear to be at much higher risk of these cancers.

\section{Supplementary Material}

Refer to Web version on PubMed Central for supplementary material.

\section{Acknowledgments}

The authors would like to thank all of the participants who took part in this research for providing us very insightful and constructive comments, which helped improve this manuscript. The INHANCE core data pooling was supported by NIH Grants (NCI R03CA113157 and NIDCR R03DE016611). The individual studies were supported by the following grants: Milan study (2006-2009): Italian Foundation for Research on Cancer (Italian Ministry of Health, General Directorate of European and International Relations) and Italian Ministry of Education (PRIN 2009 X8YCBN).Italy Multicenter study: Italian Association for Research on Cancer (AIRC), Italian League Against Cancer and Italian Ministry of Research. Swiss study: Swiss League against Cancer and the Swiss Research against Cancer/Oncosuisse (KFS-700, OCS-1633).Boston study: National Institutes of Health (NIH) US (R01CA078609, R01CA100679). Los Angeles study: National Institute of Health (NIH) US (P50CA090388, R01DA011386, R03CA077954, T32CA009142, U01CA096134, R21ES011667) and the Alper Research Program for Environmental Genomics of the UCLA Jonsson Comprehensive Cancer Center. MSKCC study: NIH (R01CA051845). North Carolina (1994-1997): National Institutes of Health (NIH) US (R01CA061188), and in part by a Grant from the National Institute of Environmental Health Sciences (P30ES010126). US Multicenter study: The Intramural Program of the NCI, NIH, United States. Japan (2001-2005): Scientific Research Grant from the Ministry of Education, Science, Sports, Culture and Technology of Japan (17015052) and Grant for the ThirdTerm Comprehensive 10-year Strategy for Cancer Control from the Ministry of Health, Labor and Welfare of Japan (H20-002). The work of EL was supported by Fondazione Veronesi and Italian Association for Research on Cancer (AIRC, Grant No. $10491-2010 / 2013$ ).

\section{References}

1. Ferlay, JSI., Ervik, M., Dikshit, R., Eser, S., Mathers, C., Rebelo, M., Parkin, DM., Forman, D., Bray, F. GLOBOCAN 2012 v1.0, Cancer Incidence and Mortality Worldwide: IARC CancerBase No 11 [Internet]. International Agency for Research on Cancer; Lyon, France: 2013. http:// globocan.iarc.fr. Accessed June 2014

2. IARC. List of Classifications by cancer sites with sufficient or limited evidence in humans, volumes 1 to 109*. http://monographs.iarc.fr/ENG/Classification/index.php. Accessed June 2014

3. WCRF/AICR. Food, nutrition, physical activity, and the prevention of cancer: a global perspective. Washington, DC: 2007.

4. Freedman ND, Park Y, Subar AF, et al. Fruit and vegetable intake and head and neck cancer risk in a large United States prospective cohort study. Int J Cancer. 2008; 122(10):2330-6. DOI: 10.1002/ijc. 23319 [PubMed: 18092323] 
5. Edefonti V, Hashibe M, Ambrogi F, et al. Nutrient-based dietary patterns and the risk of head and neck cancer: a pooled analysis in the International Head and Neck Cancer Epidemiology consortium. Ann Oncol. 2012; 23(7):1869-80. DOI: 10.1093/annonc/mdr548 [PubMed: 22123733]

6. Lucenteforte E, Garavello W, Bosetti C, La Vecchia C. Dietary factors and oral and pharyngeal cancer risk. Oral Oncol. 2009; 45(6):461-7. DOI: 10.1016/j.oraloncology.2008.09.002 [PubMed: 18990606]

7. Pavia M, Pileggi C, Nobile CG, Angelillo IF. Association between fruit and vegetable consumption and oral cancer: a meta-analysis of observational studies. Am J Clin Nutr. 2006; 83(5):1126-34. [PubMed: 16685056]

8. Riboli E, Norat T. Epidemiologic evidence of the protective effect of fruit and vegetables on cancer risk. Am J Clin Nutr. 2003; 78(3 Suppl):559S-69S. [PubMed: 12936950]

9. Chew BP, Park JS. Carotenoid action on the immune response. J Nutr. 2004; 134(1):257S-61S. [PubMed: 14704330]

10. Britton, G., Liaaen-Jensen, S., Pfander, H. Carotenoids: Handbook. Verlag, B., editor. Basel: 2004.

11. Khachik F. Distribution and metabolism of dietary carotenoids in humans as a criterion for development of nutritional supplements. Pure Appl Chem. 2006; 78(8):1551-7.

12. Paiva SA, Russell RM. Beta-carotene and other carotenoids as antioxidants. J Am Coll Nutr. 1999; 18(5):426-33. [PubMed: 10511324]

13. Suzuki T, Wakai K, Matsuo K, et al. Effect of dietary antioxidants and risk of oral, pharyngeal and laryngeal squamous cell carcinoma according to smoking and drinking habits. Cancer Sci. 2006; 97(8):760-7. DOI: 10.1111/j.1349-7006.2006.00232.x [PubMed: 16800818]

14. Prasad MP, Krishna TP, Pasricha S, Quereshi MA, Krishnaswamy K. Diet and oral cancer: a case control study. Asia Pac J Clin Nutr. 1995; 4(2):259-64. [PubMed: 24394336]

15. Zheng W, Blot WJ, Shu XO, et al. Risk factors for oral and pharyngeal cancer in Shanghai, with emphasis on diet. Cancer Epidemiol Biomarkers Prev. 1992; 1(6):441-8. [PubMed: 1302555]

16. Zheng T, Boyle P, Willett WC, et al. A case-control study of oral cancer in Beijing, People's Republic of China. Associations with nutrient intakes, foods and food groups. Eur J Cancer B Oral Oncol. 1993; 29B(1):45-55. [PubMed: 8180577]

17. Marshall JR, Graham S, Haughey BP, et al. Smoking, alcohol, dentition and diet in the epidemiology of oral cancer. Eur J Cancer B Oral Oncol. 1992; 28B(1):9-15. [PubMed: 1422474]

18. Negri E, Franceschi S, Bosetti C, et al. Selected micronutrients and oral and pharyngeal cancer. Int J Cancer. 2000; 86(1):122-7. DOI: 10.1002/(SICI)1097-0215(20000401)86:1<122:AIDIJC19>3.0.CO;2-2 [PubMed: 10728605]

19. Day GL, Blot WJ, Austin DF, et al. Racial differences in risk of oral and pharyngeal cancer: alcohol, tobacco, and other determinants. J Natl Cancer Inst. 1993; 85(6):465-73. [PubMed: 8445674]

20. Gridley G, McLaughlin JK, Block G, et al. Diet and oral and pharyngeal cancer among blacks. Nutr Cancer. 1990; 14(3-4):219-25. DOI: 10.1080/01635589009514096 [PubMed: 2084618]

21. McLaughlin JK, Gridley G, Block G, et al. Dietary factors in oral and pharyngeal cancer. J Natl Cancer Inst. 1988; 80(15):1237-43. [PubMed: 3418729]

22. Rossing MA, Vaughan TL, McKnight B. Diet and pharyngeal cancer. Int J Cancer. 1989; 44(4): 593-7. [PubMed: 2793230]

23. De Stefani E, Oreggia F, Boffetta P, Deneo-Pellegrini H, Ronco A, Mendilaharsu M. Tomatoes, tomato-rich foods, lycopene and cancer of the upper aero digestive tract: a case-control in Uruguay. Oral Oncol. 2000; 36(1):47-53. [PubMed: 10889919]

24. Bidoli E, Bosetti C, La Vecchia C, et al. Micronutrients and laryngeal cancer risk in Italy and Switzerland: a case-control study. Cancer Causes Control. 2003; 14(5):477-84. [PubMed: 12946043]

25. De Stefani E, Ronco A, Mendilaharsu M, Deneo-Pellegrini H. Diet and risk of cancer of the upper aerodigestive tract-II. Nutrients. Oral Oncol. 1999; 35(1):22-6. [PubMed: 10211306]

26. Bravi F, Bosetti C, Filomeno M, et al. Foods, nutrients and the risk of oral and pharyngeal cancer. Br J Cancer. 2013; 109(11):2904-10. DOI: 10.1038/bjc.2013.667 [PubMed: 24149181] 
27. Schantz SP, Zhang ZF, Spitz MS, Sun M, Hsu TC. Genetic susceptibility to head and neck cancer: interaction between nutrition and mutagen sensitivity. Laryngoscope. 1997; 107(6):765-81. [PubMed: 9185733]

28. Petridou E, Zavras AI, Lefatzis D, et al. The role of diet and specific micronutrients in the etiology of oral carcinoma. Cancer. 2002; 94(11):2981-8. DOI: 10.1002/cncr.10560 [PubMed: 12115387]

29. Kune GA, Kune S, Field B, et al. Oral and pharyngeal cancer, diet, smoking, alcohol, and serum vitamin A and beta-carotene levels: a case-control study in men. Nutr Cancer. 1993; 20(1):61-70. DOI: 10.1080/01635589309514271 [PubMed: 8415131]

30. Gallus S, Bosetti C, Franceschi S, Levi F, Negri E, La Vecchia C. Laryngeal cancer in women: tobacco, alcohol, nutritional, and hormonal factors. Cancer Epidemiol Biomarkers Prev. 2003; 12(6):514-7. [PubMed: 12814996]

31. Esteve J, Riboli E, Pequignot G, et al. Diet and cancers of the larynx and hypopharynx: the IARC multi-center study in southwestern Europe. Cancer Causes Control. 1996; 7(2):240-52. [PubMed: 8740737]

32. Conway DI, Hashibe M, Boffetta P, et al. Enhancing epidemiologic research on head and neck cancer: INHANCE - the international head and neck cancer epidemiology consortium. Oral Oncol. 2009; 45(9):743-6. DOI: 10.1016/j.oraloncology.2009.02.007 [PubMed: 19442571]

33. Hashibe M, Brennan P, Benhamou S, et al. Alcohol drinking in never users of tobacco, cigarette smoking in never drinkers, and the risk of head and neck cancer: pooled analysis in the International Head and Neck Cancer Epidemiology Consortium. J Natl Cancer Inst. 2007; 99(10): 777-89. DOI: 10.1093/jnci/djk179 [PubMed: 17505073]

34. Wyss A, Hashibe M, Chuang SC, et al. Cigarette, cigar, and pipe smoking and the risk of head and neck cancers: pooled analysis in the International Head and Neck Cancer Epidemiology consortium. Am J Epidemiol. 2013; 178(5):679-90. DOI: 10.1093/aje/kwt029 [PubMed: 23817919]

35. Chuang SC, Jenab M, Heck JE, et al. Diet and the risk of head and neck cancer: a pooled analysis in the INHANCE consortium. Cancer Causes Control. 2012; 23(1):69-88. DOI: 10.1007/ s10552-011-9857-x

36. Galeone C, Edefonti V, Parpinel M, et al. Folate intake and the risk of oral cavity and pharyngeal cancer: a pooled analysis within the International Head and Neck Cancer Epidemiology consortium. Int J Cancer. 2014; doi: 10.1002/ijc.29044

37. Scott, DW. Multivariate density estimation: theory, practice and visualization. New York, NY: Wiley; 2005.

38. Willett W, Stampfer MJ. Total energy intake: implications for epidemiologic analyses. Am J Epidemiol. 1986; 124(1):17-27. [PubMed: 3521261]

39. Hosmer, DW., Lemeshow, S. Applied logistic regression. 2nd. New York, NY: Wiley; 2000.

40. R Core Team. R: a language and environment for statistical computing. R Foundation for Statistical Computing; Vienna, Austria: 2013. http://www.R-project.org

41. Zheng W, Sellers TA, Doyle TJ, Kushi LH, Potter JD, Folsom AR. Retinol, antioxidant vitamins, and cancers of the upper digestive tract in a prospective cohort study of postmenopausal women. Am J Epidemiol. 1995; 142(9):955-60. [PubMed: 7572976]

42. La Vecchia C, Negri E, D’ Avanzo B, Boyle P, Franceschi S. Dietary indicators of oral and pharyngeal cancer. Int J Epidemiol. 1991; 20(1):39-44. [PubMed: 2066242]

43. Mackerras D, Buffler PA, Randall DE, Nichaman MZ, Pickle LW, Mason TJ. Carotene intake and the risk of laryngeal cancer in coastal Texas. Am J Epidemiol. 1988; 128(5):980-8. [PubMed: 3189297]

44. Freudenheim JL, Graham S, Byers TE, et al. Diet, smoking, and alcohol in cancer of the larynx: a case-control study. Nutr Cancer. 1992; 17(1):33-45. DOI: 10.1080/01635589209514171 [PubMed: 1574443]

45. Franceschi S, Bidoli E, Baron AE, et al. Nutrition and cancer of the oral cavity and pharynx in north-east Italy. Int J Cancer. 1991; 47(1):20-5. [PubMed: 1985874]

46. Krinsky NI, Johnson EJ. Carotenoid actions and their relation to health and disease. Mol Aspects Med. 2005; 26(6):459-516. DOI: 10.1016/j.mam.2005.10.001 [PubMed: 16309738] 
47. Fiedor J, Burda K. Potential role of carotenoids as antioxidants in human health and disease. Nutrients. 2014; 6(2):466-88. DOI: 10.3390/nu6020466 [PubMed: 24473231]

48. De Luca L, Maestri N, Bonanni F, Nelson D. Maintenance of epithelial cell differentiation: the mode of action of vitamin A. Cancer. 1972; 30(5):1326-31. [PubMed: 5083067]

49. Sporn MB, Roberts AB. Role of retinoids in differentiation and carcinogenesis. Cancer Res. 1983; 43(7):3034-40. [PubMed: 6189589]

50. Edefonti V, Hashibe M, Parpinel M, et al. Natural vitamin C intake and the risk of head and neck cancer: a pooled analysis in the International Head and Neck Cancer Epidemiology consortium. Int J Cancer. 2014; doi: 10.1002/ijc.29388

51. Willett, WC. Nutritional epidemiology. 2nd. New York: Oxford University Press; 1998.

52. Toporcov TN, Tavares GE, Rotundo LD, et al. Do tobacco and alcohol modify protective effects of diet on oral carcinogenesis? Nutr Cancer. 2012; 64(8):1182-9. DOI: 10.1080/01635581.2012.721155 [PubMed: 23163847]

53. Albanes D, Heinonen OP, Taylor PR, et al. Alpha-tocopherol and beta-carotene supplements and lung cancer incidence in the alpha-tocopherol, beta-carotene cancer prevention study: effects of base-line characteristics and study compliance. J Natl Cancer Inst. 1996; 88(21):1560-70. [PubMed: 8901854]

54. Edefonti V, Bravi F, La Vecchia C, et al. Nutrient-based dietary patterns and the risk of oral and pharyngeal cancer. Oral Oncol. 2010; 46(5):343-8. DOI: 10.1016/j.oraloncology.2009.11.017 [PubMed: 20226721]

55. Castenmiller JJ, West CE. Bioavailability and bioconversion of carotenoids. Annu Rev Nutr. 1998; 18:19-38. DOI: 10.1146/annurev.nutr.18.1.19 [PubMed: 9706217]

56. Yeum KJ, Russell RM. Carotenoid bioavailability and biocon-version. Annu Rev Nutr. 2002; 22:483-504. DOI: 10.1146/annurev.nutr.22.010402.102834 [PubMed: 12055355]

57. Berry EM, Dal Maso L, Franceschi S. Synergism between vitamins E and C: biological implications for future research. Int J Cancer. 1999; 83(2):288. [PubMed: 10471541]

58. Leffondre K, Abrahamowicz M, Siemiatycki J, Rachet B. Modeling smoking history: a comparison of different approaches. Am J Epidemiol. 2002; 156(9):813-23. [PubMed: 12396999]

59. Stram DO, Huberman M, Wu AH. Is residual confounding a reasonable explanation for the apparent protective effects of beta-carotene found in epidemiologic studies of lung cancer in smokers? Am J Epidemiol. 2002; 155(7):622-8. [PubMed: 11914189]

60. Marshall JR, Hastrup JL. Mismeasurement and the resonance of strong confounders: uncorrelated errors. Am J Epidemiol. 1996; 143(10):1069-78. [PubMed: 8629614]

61. Brewer MS. Natural antioxidants: sources, compounds, mechanisms of action, and potential applications. Compr Rev Food Sci Food Saf. 2011; 10:221-47. DOI: 10.1111/j. 1541-4337.2011.00156.x 

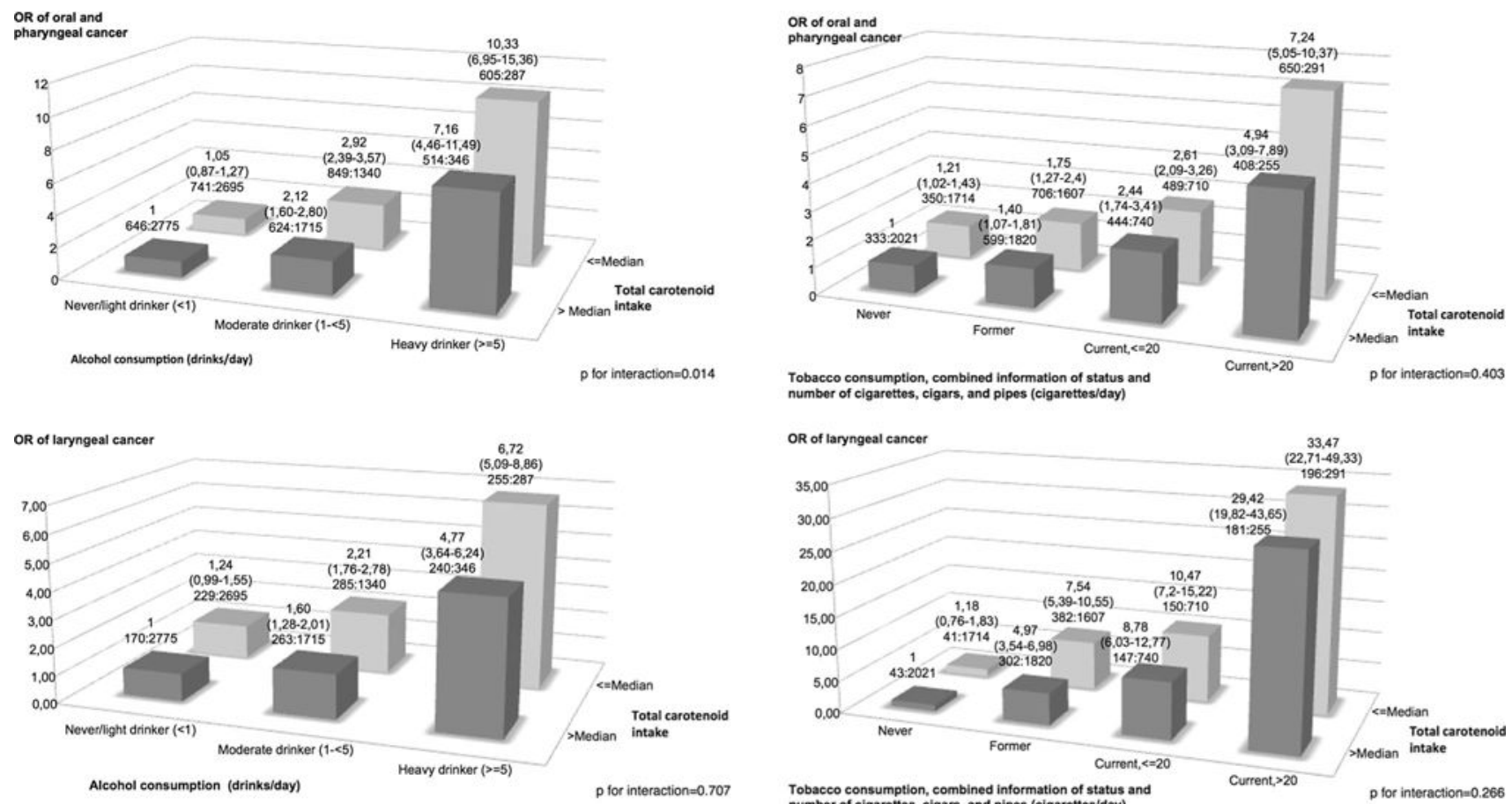

Fig. 1.

Odds ratios and $95 \%$ confidence intervals for combinations of total carotenoids intake with tobacco smoking and alcohol drinking among 18,207 subjects: 4414 with oral and pharyngeal cancer, 1545 with laryngeal cancer, and 12,248 controls 


\section{올}

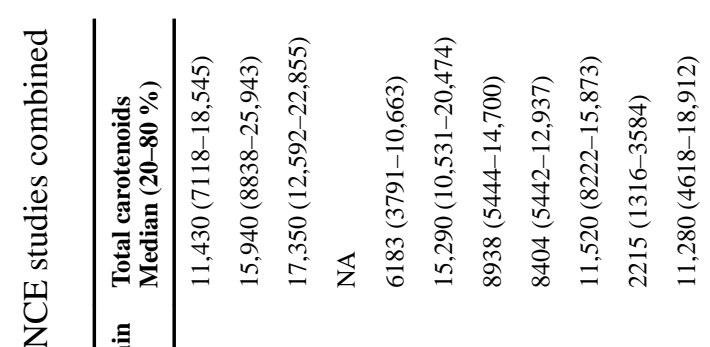

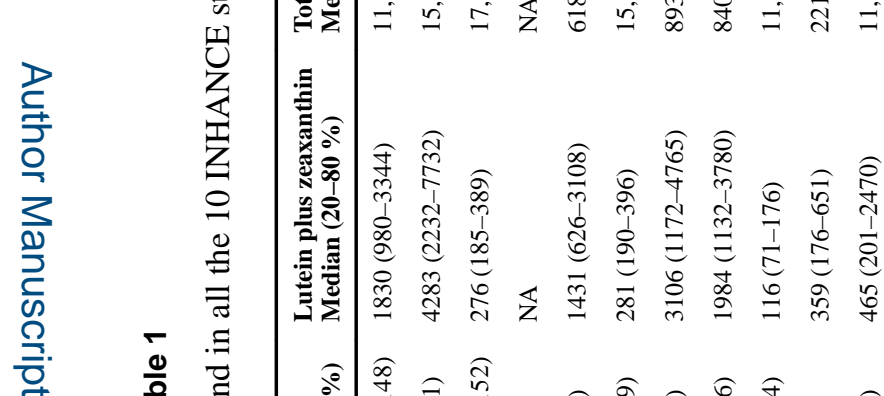

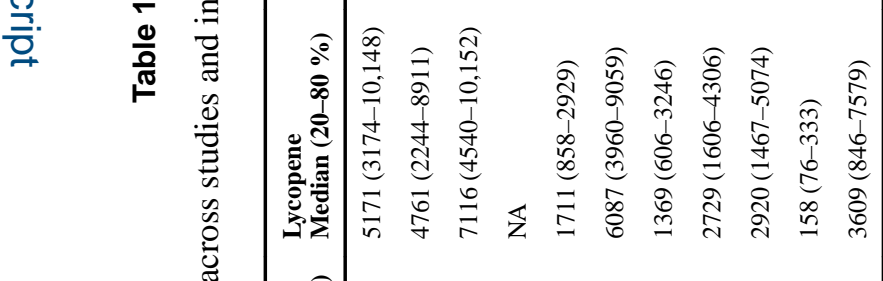

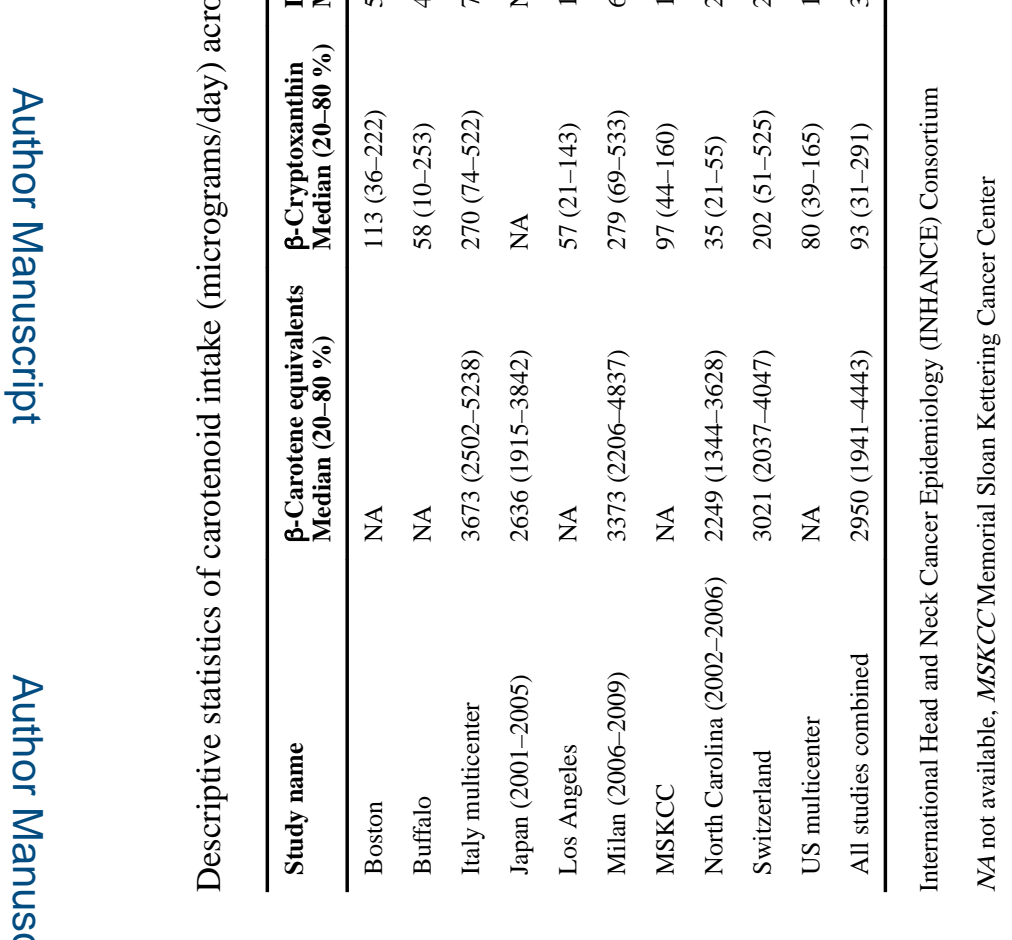

ב্

Eur J Epidemiol. Author manuscript; available in PMC 2017 August 10. 


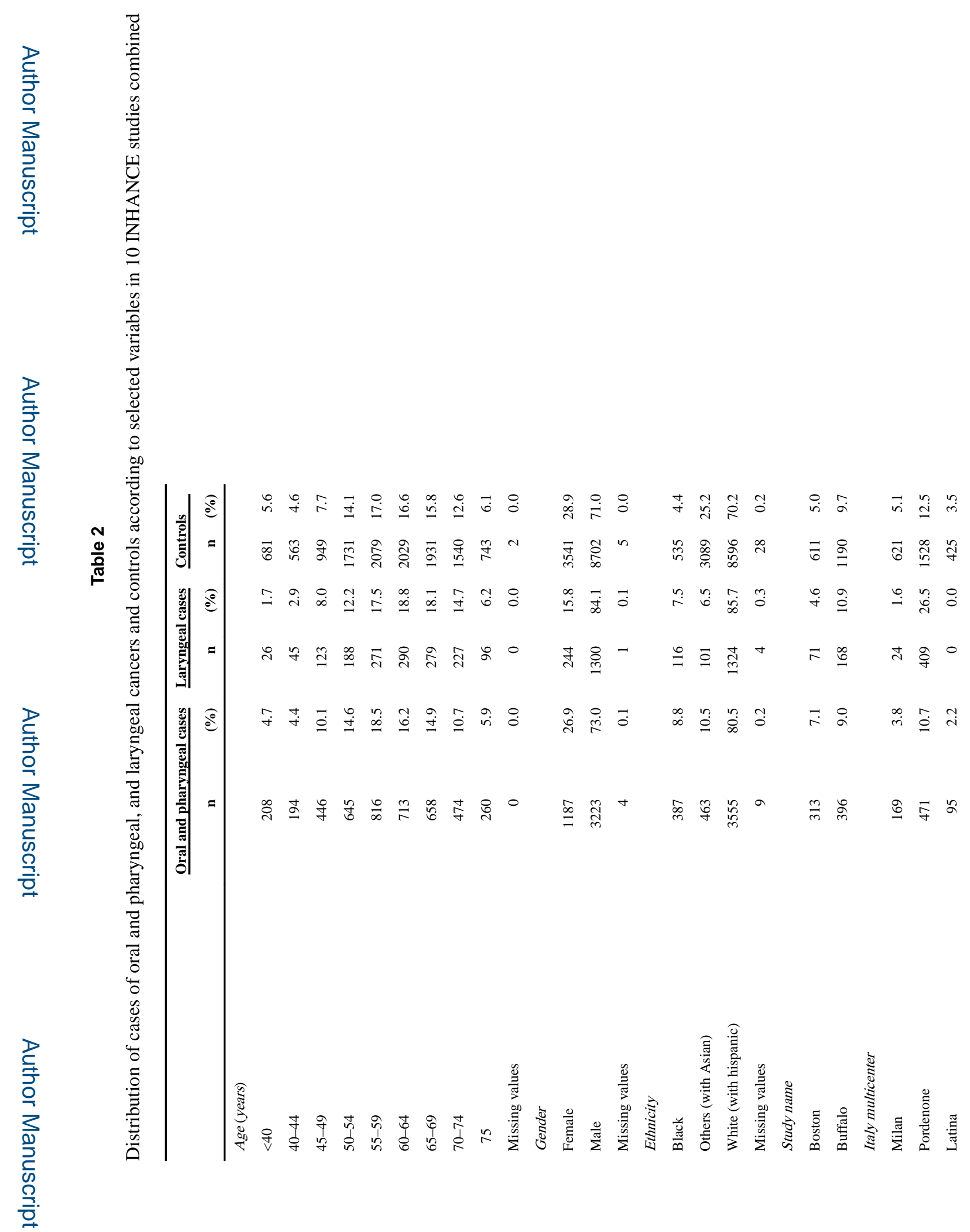

Eur J Epidemiol. Author manuscript; available in PMC 2017 August 10. 


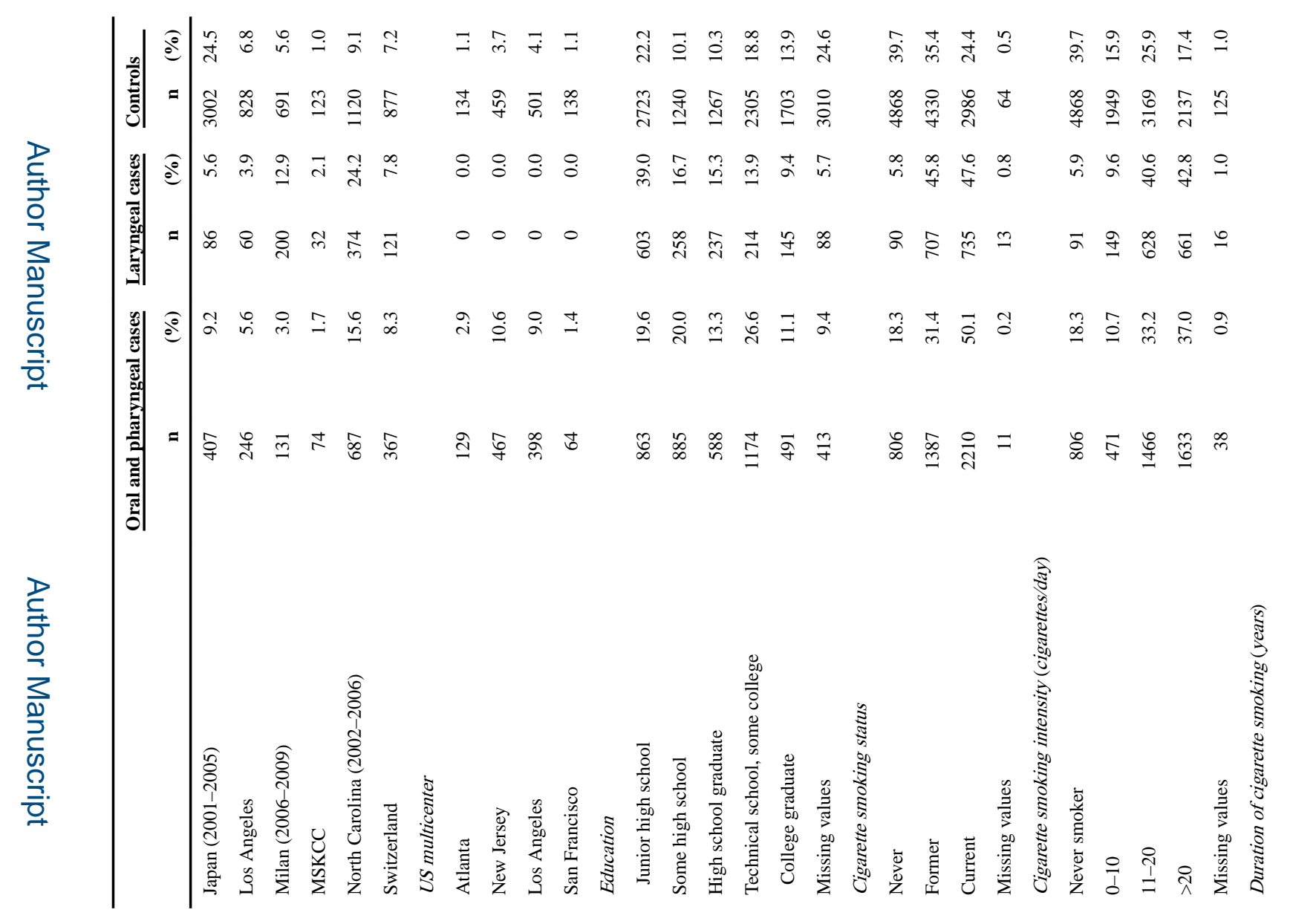

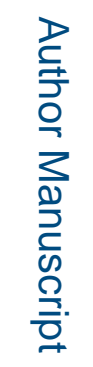

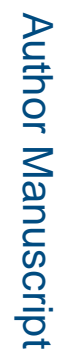

Eur J Epidemiol. Author manuscript; available in PMC 2017 August 10. 


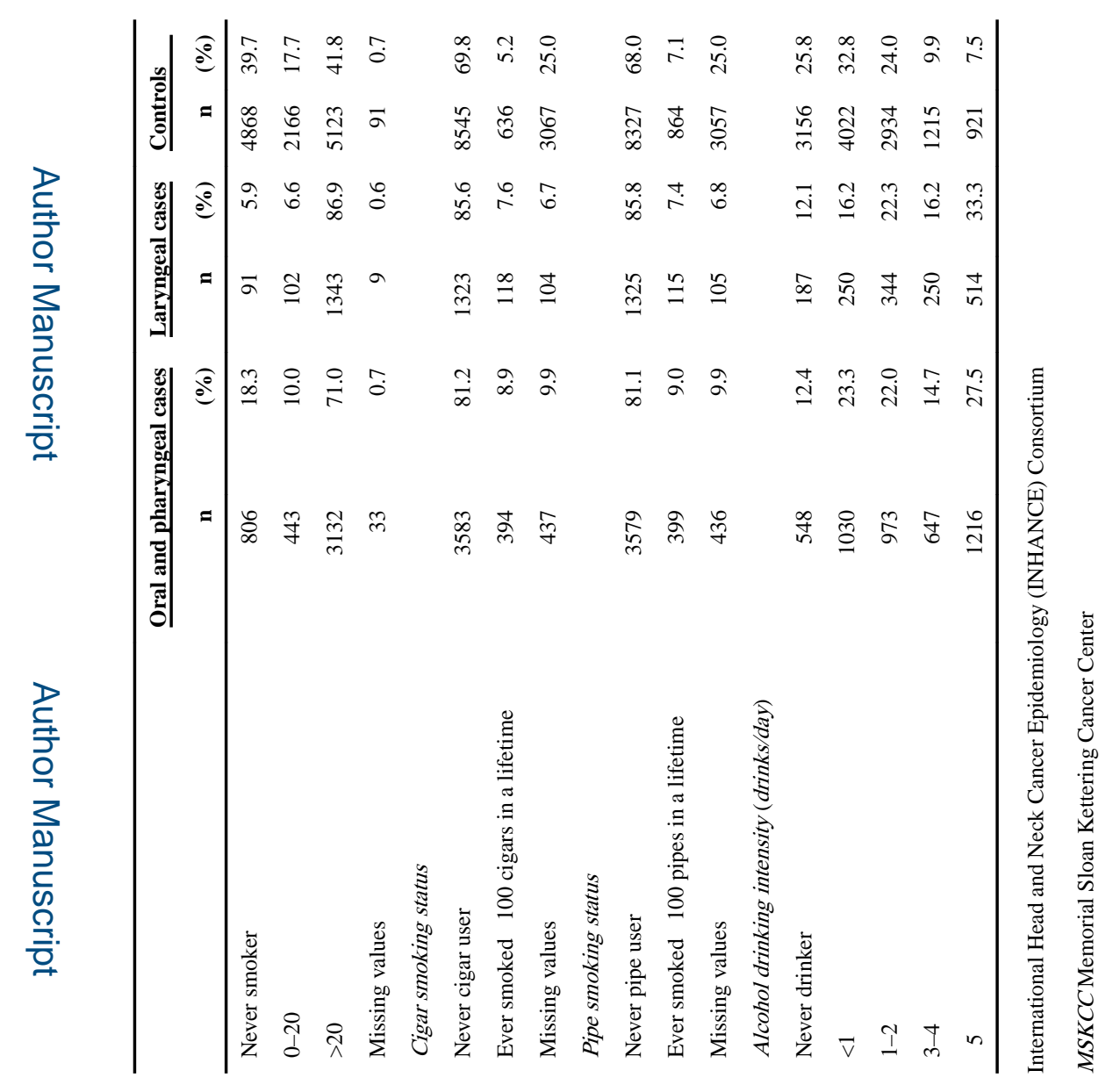

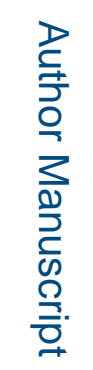

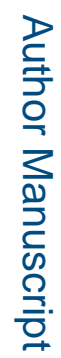

Eur J Epidemiol. Author manuscript; available in PMC 2017 August 10. 


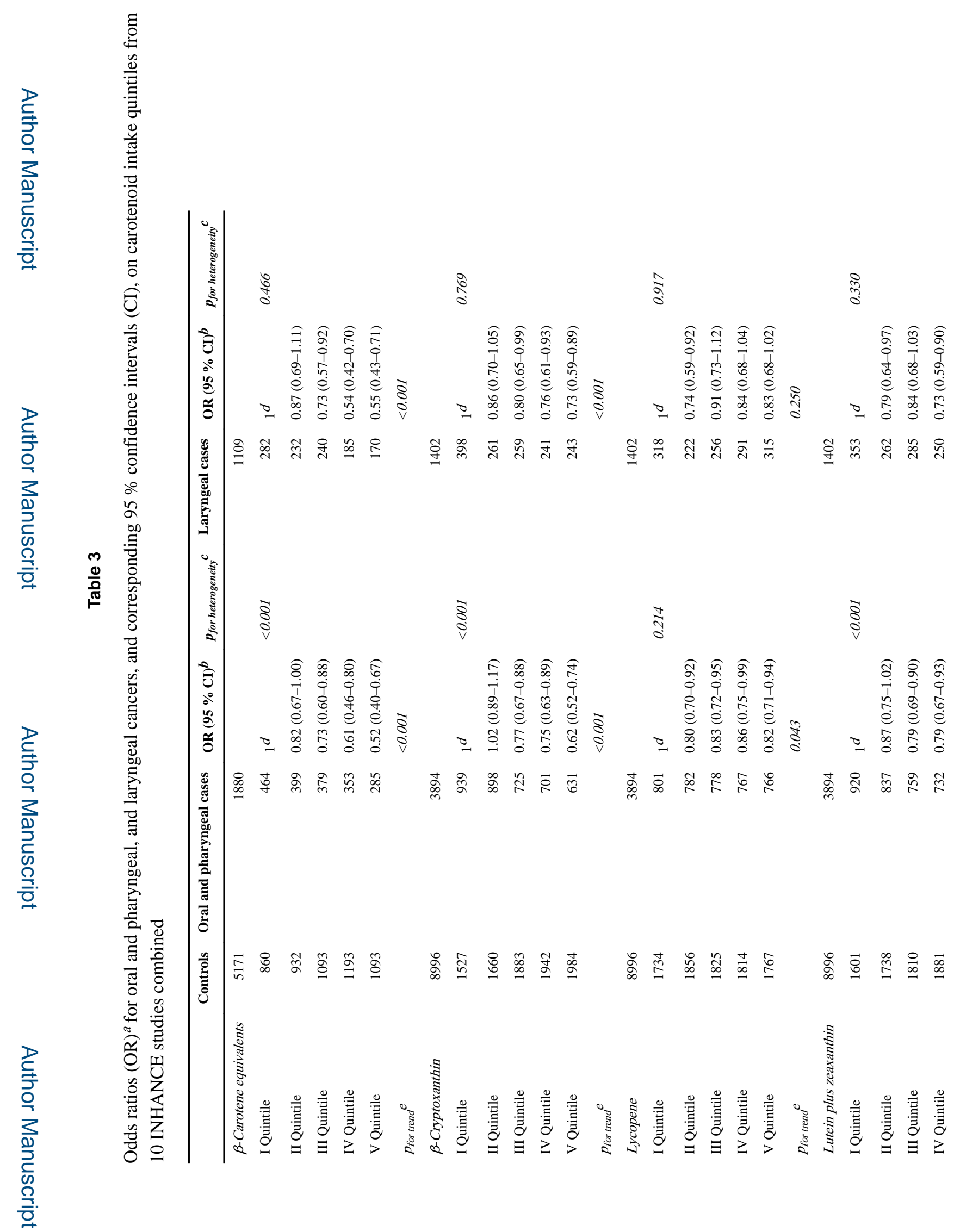

Eur J Epidemiol. Author manuscript; available in PMC 2017 August 10. 


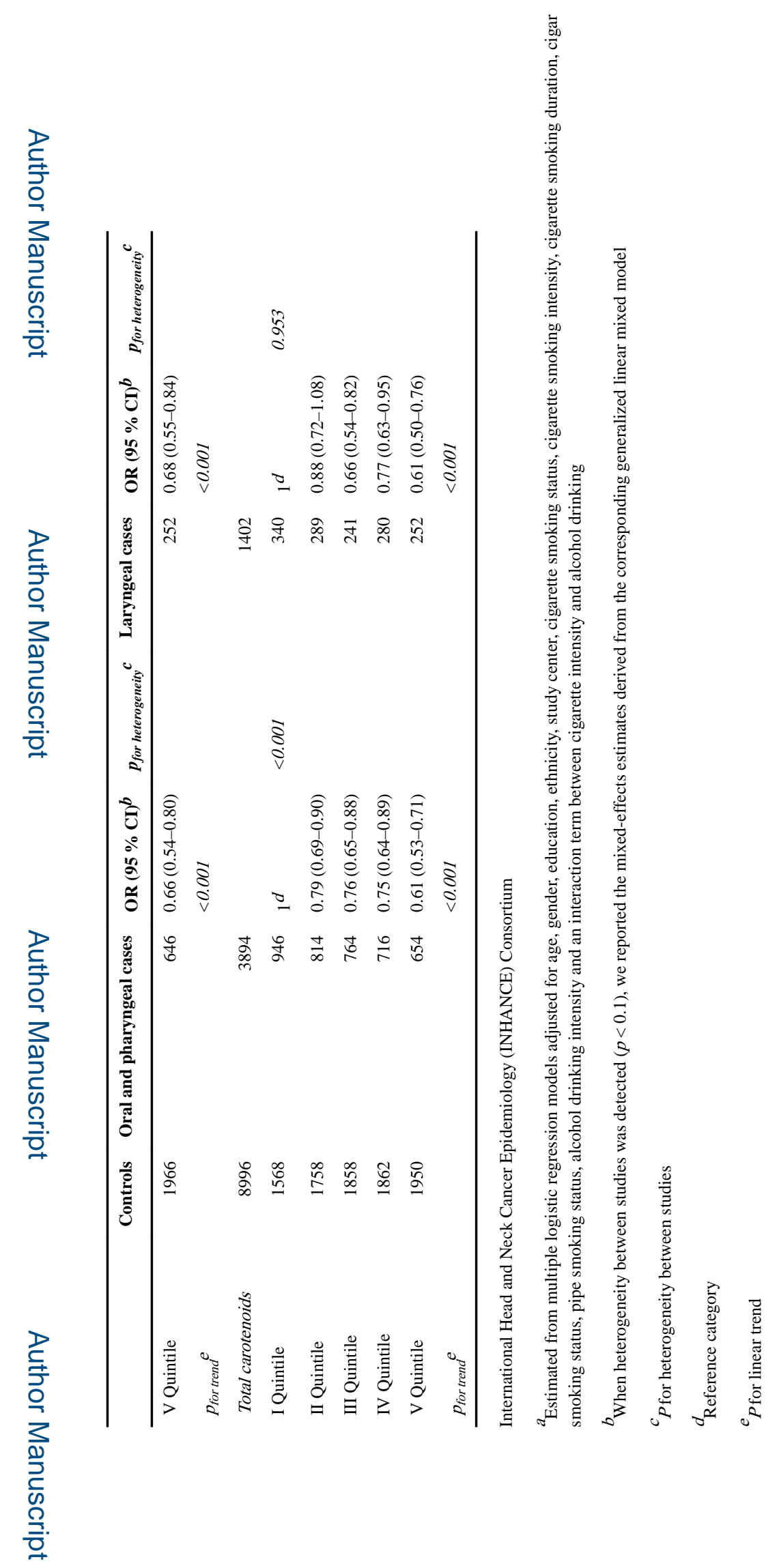

Eur J Epidemiol. Author manuscript; available in PMC 2017 August 10. 


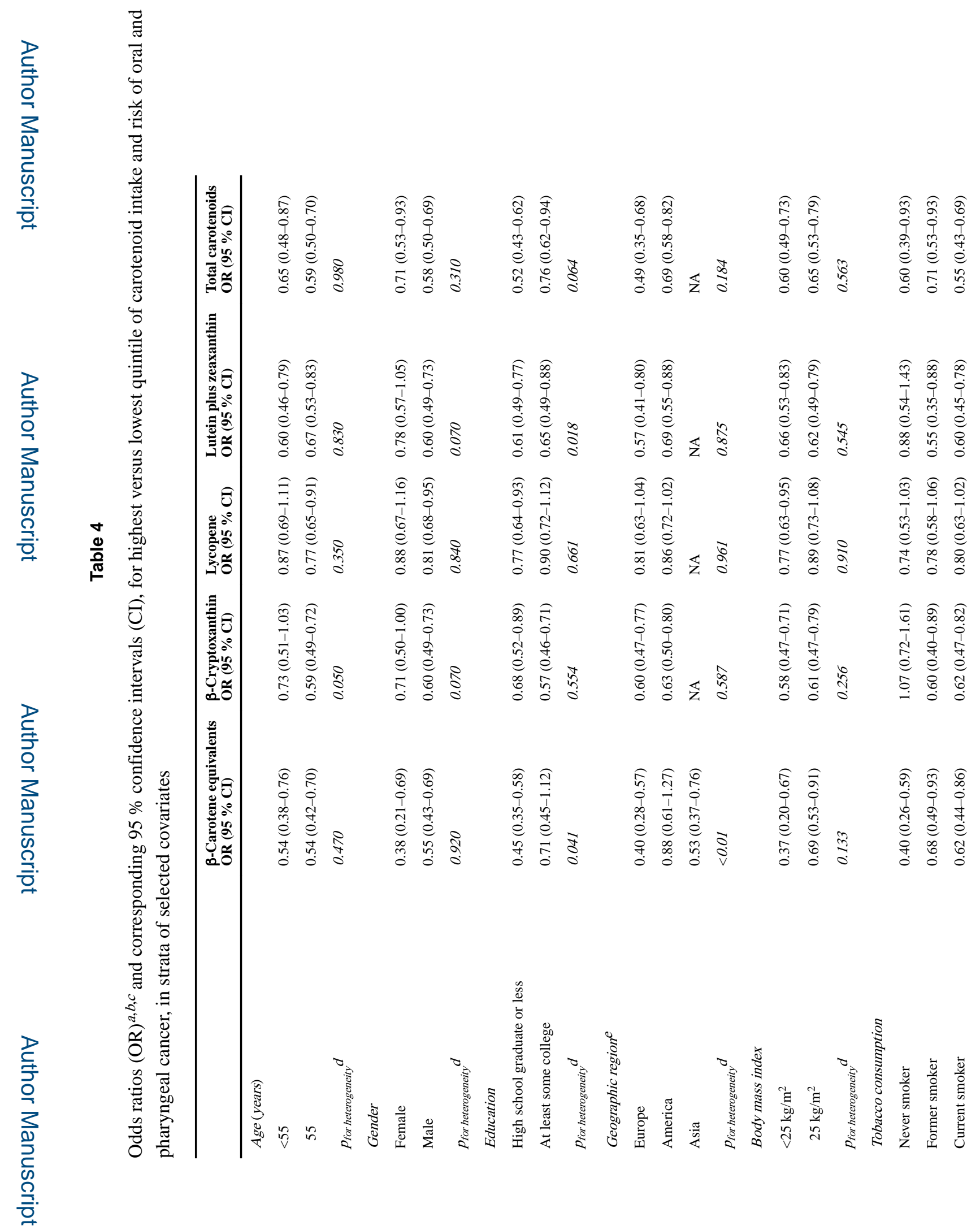

Eur J Epidemiol. Author manuscript; available in PMC 2017 August 10. 


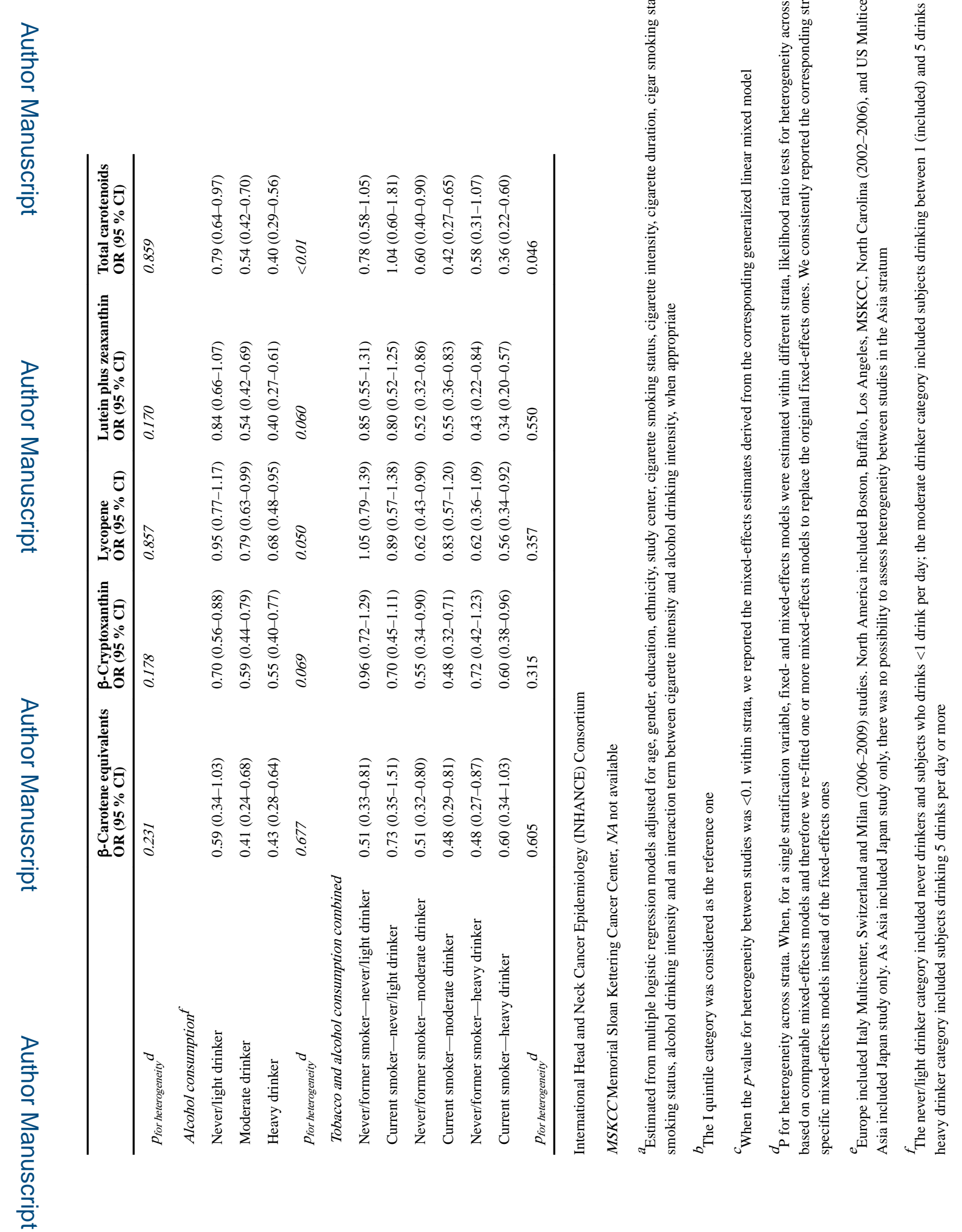

Eur J Epidemiol. Author manuscript; available in PMC 2017 August 10. 


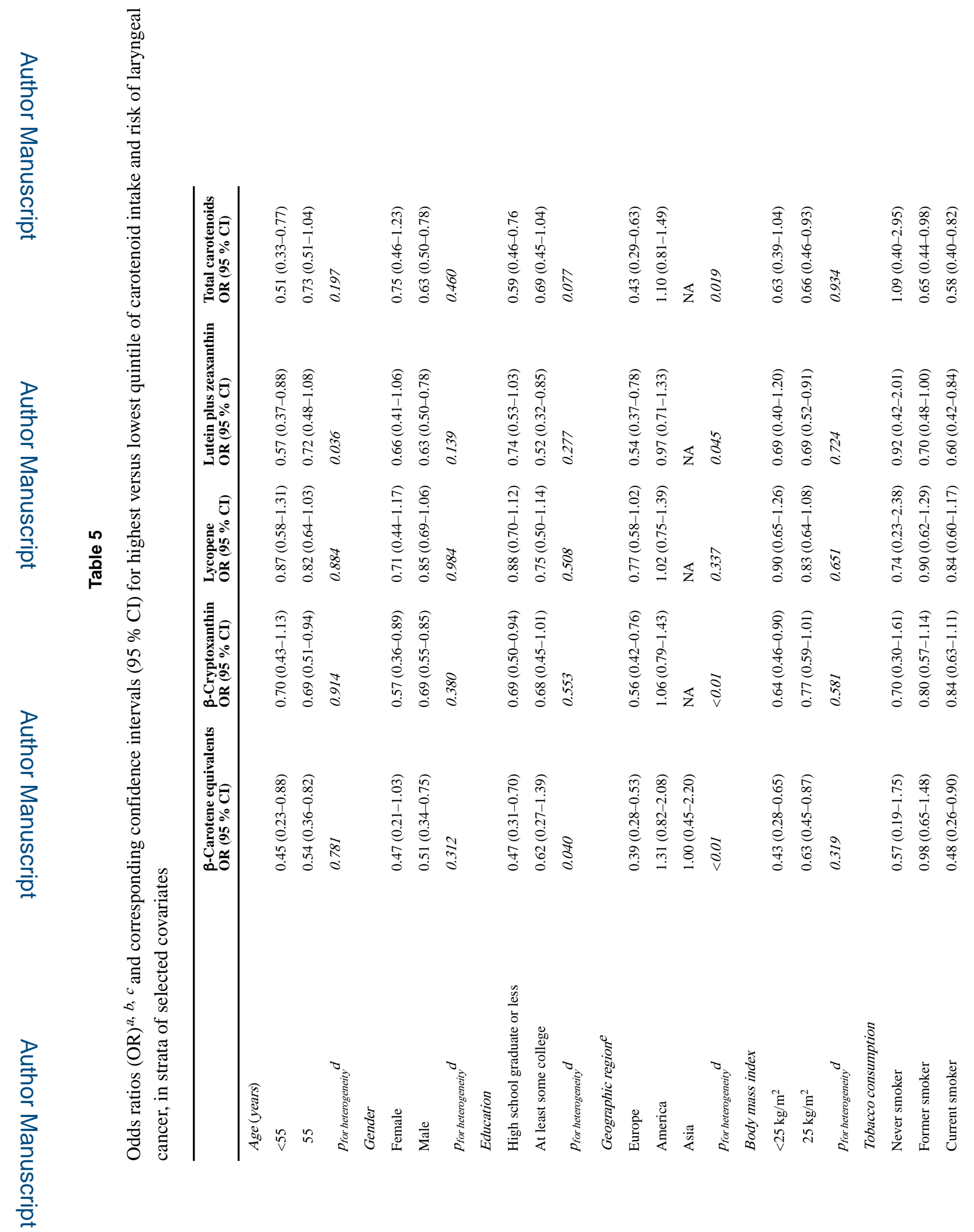

Eur J Epidemiol. Author manuscript; available in PMC 2017 August 10. 


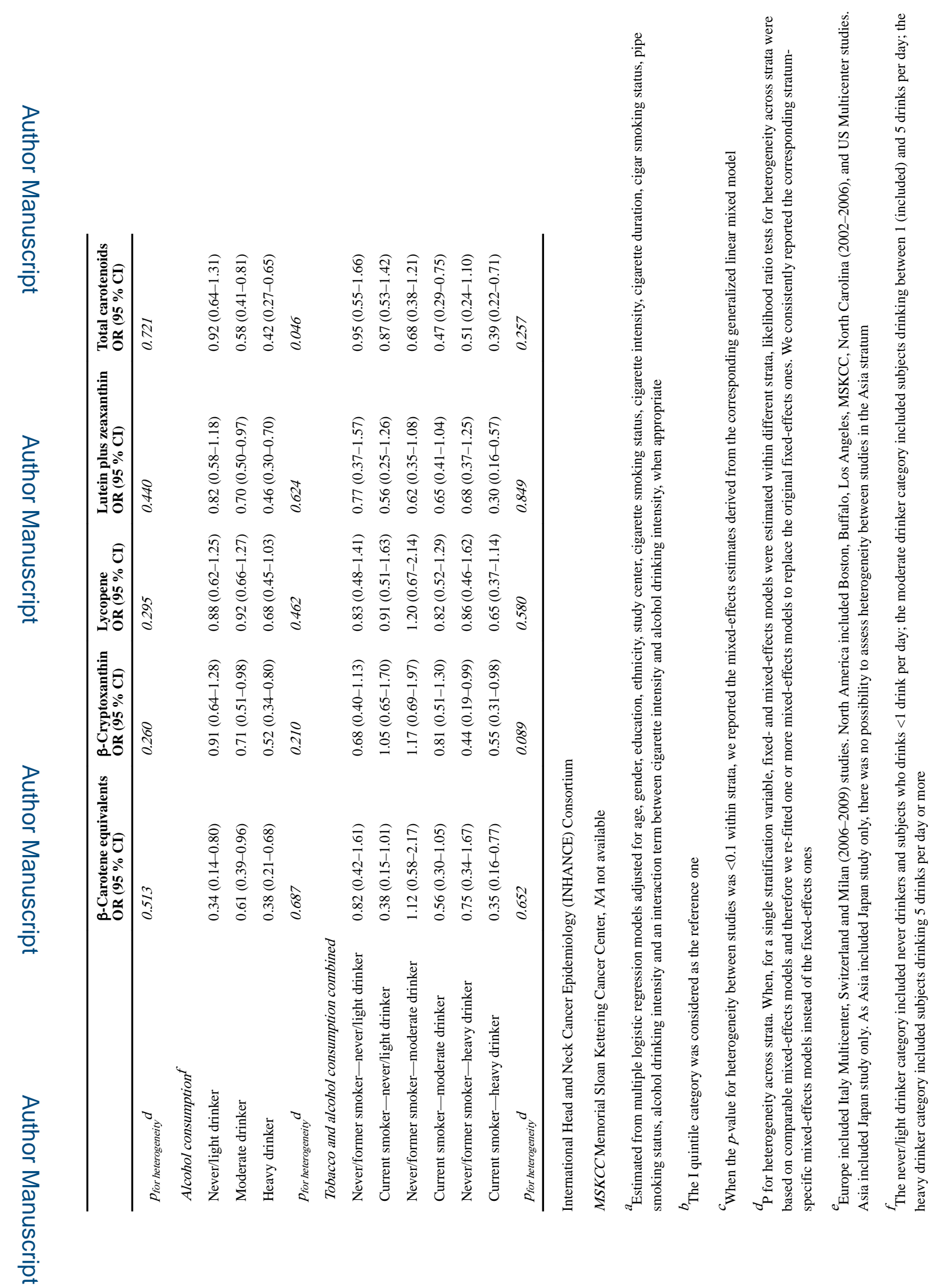

Eur J Epidemiol. Author manuscript; available in PMC 2017 August 10. 